\title{
Transient Performance Simulation of Aircraft Engine Integrated with Fuel and Control Systems
}

\author{
C. Wang ${ }^{1}$ and Y.G. $\mathrm{Li}^{2}$ \\ School of Aerospace, Transport and Manufacturing, Cranfield University, Bedford, UK \\ B.Y. Yang ${ }^{3}$ \\ Beijing HangKe Engine Control System Technology Co. Ltd., Beijing, China
}

\begin{abstract}
A new method for the simulation of gas turbine fuel systems based on an intercomponent volume method has been developed. It is able to simulate the performance of each of the hydraulic components of a fuel system using physics-based models, which potentially offers more accurate results compared with those using transfer functions. A transient performance simulation system has been set up for gas turbine engines based on an inter-component volume (ICV) method. A proportional-integral (PI) control strategy is used for the simulation of engine controller. An integrated engine and its control and hydraulic fuel systems has been set up to investigate their coupling effect during engine transient processes. The developed simulation system has been applied to a model aero engine. The results show that the delay of the engine transient response due to the inclusion of the fuel system model is noticeable although relatively small. The developed method is generic and can be applied to any other gas turbines and their control and fuel systems.
\end{abstract}

Key Words: Gas turbine, engine, control, transient performance, fuel system, simulation

\section{Nomenclature}

$A \quad=\quad \operatorname{area}\left(\mathrm{m}^{2}\right)$

$B \quad=$ bulk modulus $(\mathrm{Pa})$

\footnotetext{
${ }^{1} \mathrm{PhD}$ student, School of Aerospace, Transport and Manufacturing, Cranfield University.

${ }^{2}$ Senior Lecturer, School of Aerospace, Transport and Manufacturing, Cranfield University.

${ }^{3}$ Senior Engineer, Beijing HangKe Engine Control System Technology Co. Ltd.
} 


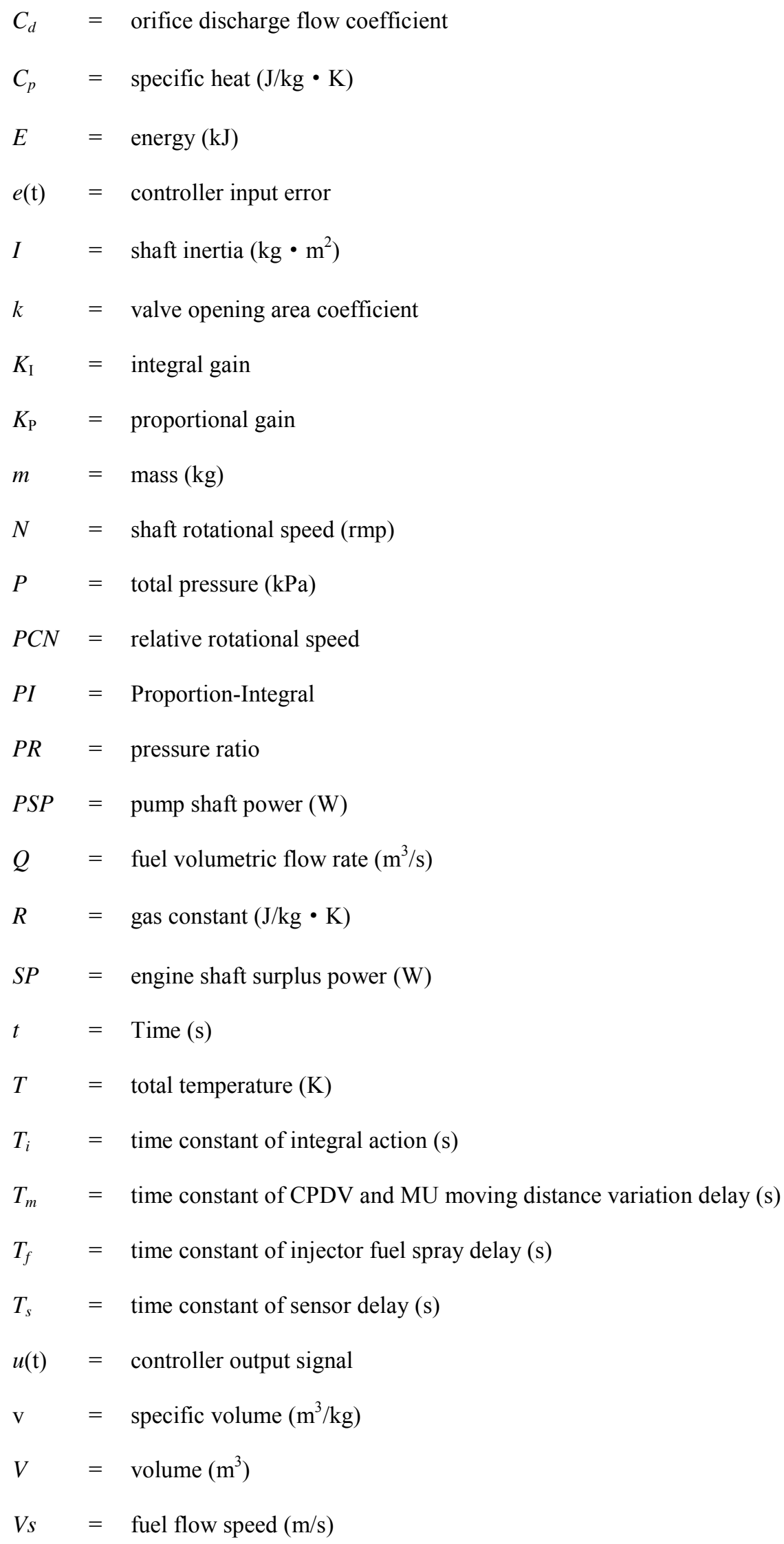


$W \quad=\quad$ fuel mass flow rate $(\mathrm{kg} / \mathrm{s}) ; \operatorname{power}(\mathrm{W})$

$\triangle X d=$ orifice moving distance $(\mathrm{m})$

\section{Greek Letters}

$$
\begin{aligned}
\eta & =\text { pump efficiency }(\%) \\
\rho & =\text { density }\left(\mathrm{kg} / \mathrm{m}^{3}\right) \\
\phi & =\text { thermal energy }(\mathrm{J}) \\
\Delta & =\text { difference } \\
c & =\text { compressor } \\
f f & =\text { fuel flow } \\
\text { in } & =\text { component inlet } \\
\text { out } & =\text { component outlet } \\
t \quad & =\text { turbine }
\end{aligned}
$$

\section{Subscripts}

\section{Introduction}

Performance simulations have been widely used in modern gas turbine engine designs in order to shorten design cycles and reduce development costs. Engine transient performance simulation is very useful in the initial stage of engine development. For example, it may be used to assess the safety of transient operations of new engines and to provide a numerical test-bed for the development of control systems. However, it is found in the literature that fuel systems, as part of the fuel control and delivery systems have been ignored in gas turbine transient performance simulations and represented by a transfer function.

An engine system, a controller, sensors, and a hydraulic fuel system are four basic elements of a gas turbine propulsion system. Most currently developed engine performance modeling systems, such as NPSS [1-3], CMAPSS [4-5], Turbomatch [6-7], GasTurb [8-9], GSP [10], TERTS [11], T-MATS [12] and performance modeling such as [13] only focus on the simulation of engine systems and possibly their controllers but ignore the sensors and actuators or treat them as first order lags [14]. Such simplification may cause noticeable prediction errors. In the 
operation of gas turbine propulsion systems, fuel flow injected into an engine combustor is not only decided by the controller, but also affected by the execution of fuel control actuators [15]. Therefore, fuel output delay and fluctuation due to fuel system response will directly affect engine combustion and engine performance.

An inter-component volume (ICV) method for gas turbine transient performance simulation was firstly introduced by Fawke and Saravanamuttoo [16]. A comparison of ICV method and a constant mass flow (CMF) method for engine transient simulation was also provided in [16]. Further simulation capability and computer software for both steady and transient performance simulations of gas turbines, such as DYNGEM [17], HYDES [18] and GENENG [19] were also reported. At that time, both the ICV and the CMF methods were thoroughly analyzed and used for the steady and transient performance simulations of gas turbine engines.

In this paper, the ICV method [16] has been further developed and used in the performance simulation of hydraulic fuel systems. A gas turbine transient performance simulation system and a hydraulic fuel system model based on the ICV method have been developed. An integrated engine, controller and hydraulic fuel system has been set up and used to simulate the performance of a model turbojet engine to demonstrate the effectiveness of the method. Results of the model engine with and without the hydraulic fuel system model have been provided and compared with each other to demonstrate the impact of the fuel system model on engine transient performance. Relevant discussions and conclusions are provided accordingly.

\section{Methodology}

\subsection{Transient Performance Simulation with ICV Method for Gas Turbine Engine}

Engine transient performance simulation is used to investigate the engine dynamic behavior such as that during acceleration or deceleration processes. Although the continuation of energy, mass and momentum is still satisfied, equilibrium of work, mass flow, and heat transfer within an engine system will be broken during a transient process, which is different from that at the engine steady state conditions. Two different transient performance simulation methods are available, i.e. the Continuous Mass Flow (CMF) method [20] and the Inter-Component Volume (ICV) method [16]. In this study, the ICV method is used.

Fig. 1 shows a typical single-spool turbojet model engine used in this study. It consists of an intake, a compressor, a splitter which extracts an air stream for turbine cooling, a combustor, a mixer to simulate cooling 
mixing, a turbine driving the compressor, and a nozzle. Working fluid is assumed to be air in cold sections and gas in hot sections.

The following are three most important factors in transient performance simulations .

The first is the unbalance of work between the components on the same shaft represented by Eq. (1)

$$
\frac{d N}{d t}=\frac{3600 \cdot S P}{4 \pi^{2} I N}
$$

The second is the consideration of volume dynamics in a volume between adjecent components where the mass flow going into the volume may be different from that going out of the volume causing accumulation or dispersion of mass in the volume. Two inter-component volumes (A and B) are shown in Fig. 1 for the model engine. As the temperature variations within a gas turbine engine are mainly caused by the compression, expansion or combustion in key gas path components, the minor temperature variation in inter-component volumes may be ignored when the variation of ICV pressure is estimated. Therefore, the volume dynamics and also the variation of ICV pressure may be represented by Eq. (2) based on the equation of state for perfect gas [16, 21].

$$
d P=\frac{R T}{V} d m
$$

The third factor is the fuel flow rate provided by fuel control and delivery systems to be discussed in details later. More details of the ICV method can be found in [21].

\subsection{Control System}

The engine fuel control is a two-step process where three fuel schedules are designed for steady state, acceleration and deceleration respectively. These fuel schedules schematically shown in Fig. 2 provide required fuel

flow rate $W_{f f}$ signal to the fuel system based on the demand and measured engine relative rotational speed $P C N$ that is the handle of the engine.

As shown in Fig. 2, the steady state fuel schedule is represented by a dash line. In order to ensure a quick and safe engine transient process, a minimum fuel selection logic called "Low Win Logic" and a maximum fuel selection logic called "High Win Logic" are embedded into the fuel schedule. At an initial phase of acceleration or deceleration, a fuel controller may predict a required fuel flow rate based on cockpit shaft speed command and the measured shaft speed. Such predicted fuel flow rate may be larger than the one limited by the fuel selection logic. In 
this situation, fuel flow rate will be regulated by the fuel selection logic. When the engine approaches the desired end point of the transient process, the fuel flow rate provided by the fuel controller will become smaller than that estimated by the fuel selection logic. When that happens, the control process goes into second step where the fuel controller will take over the fuel control until the engine reaches its desired steady state. Such process is represented in Fig. 3.

A proportional-integral-derivative (PID) controller may be used in the second step when the fuel controller takes over the fuel control. It is a well-developed technology [22] and the interested readers may refer to reference [23] for more details. For simplicity only the PI controller has been selected to control the transient operation of the engine. Eq. (3) is the mathematical representation of the PI control algorithm. [24]

$$
u(t)=K_{P} e(t)+K_{I} \frac{1}{T_{i}} \int_{0}^{t} e(\tau) d \tau
$$

\subsection{Fuel System}

A fuel system is typically a hydraulic system to deliver required fuel to an engine to maintain its operation. A typical fuel system shown in Fig. 4 may consist a low pressure pump (LPP), high pressure pump (HPP), metering unit (MU), constant pressure differential valve (CPDV), throttle, injector and tubes connecting these components.

\subsubsection{Inter-Component Volumes (ICV)}

Fuel system components are connected by tubes or ducts, named as inter-component volumes, filled with pressurized fuel fluid. During a transient process, the pressure inside the volume may vary due to the inconsistent fuel flow entering and leaving the volume. In this study, the ICV method [21] normally used for engine performnce simulations is introduced into the performance simulation of a hydraulic fuel system. A typical inter-component volume may be schematically represented by Fig. 5 .

It is assumed that the system running time is firstly divided into a series of calculation time steps. The system state is then calculated at each small time step when the system is regarded as pseudo-steady and the transient process is calculated from one time step to the other. 
Volume state is governed by the conservation of mass, energy and momentum. The conservation of mass is represented by Eq. (4)

$$
m_{i+1}=m_{i}+\left(\sum W_{i_{i n}}-\sum W_{i_{o u t}}\right) \times \Delta t
$$

The fuel mass flow rate $W_{f f}$ can be calculated by Eq. (5).

$$
W_{f f}=\rho \times Q
$$

The conservation of energy is represented by Eq. (6)

$$
T_{i+1}=\frac{\sum E_{i_{\text {int }}}+E_{i}-\sum E_{i_{\text {out }}}-\frac{1}{2} m_{i+1} V s_{i+1}^{2}}{m_{i+1} C p_{i+1}}
$$

where

$$
\begin{gathered}
E=m \times C p \times T+\frac{1}{2} m \times V s^{2} \\
\boldsymbol{V} \boldsymbol{s}=\boldsymbol{Q} / \boldsymbol{A}
\end{gathered}
$$

The conservation of momentum is represented by Eq. (9).

$$
V s_{i+1}=\frac{\sum\left(m_{i} V s_{i}\right)_{\text {in }}+\left(m_{i} V s_{i}\right)-\sum\left(m_{i} V s_{i}\right)_{o u t}}{m_{i+1}}
$$

In addition, the following three assumptions are made:

- The fuel entering the volume is fully mixed immediately with the fuel already in the volume;

- The status of the fuel within a volume is kept unchanged within a time step;

- The fuel flow within a volume experiences an isothermal process.

Based on the equation of state, the volume pressure change $d P$ produced by the fuel specific volume change $d v$ can be estimated by Eq. (10).

$$
d P=-\frac{B}{v} \times d v
$$

where $d v$ may be given by Eq. (11). 


$$
d v=\left(\sum Q_{\text {in }}-\sum Q_{\text {out }}\right) /\left(\sum \rho_{\text {in }} Q_{\text {in }}-\sum \rho_{\text {out }} Q_{\text {out }}\right)
$$

where $Q_{\text {in }}$ and $Q_{\text {out }}$ are determined by the volumetric flow of upstream and downstream components of the volume.

Therefore, the new volume pressure at next time step $P_{i+1}$ is calculated by Eq. (12).

$$
P_{i+1}=P_{i}+d P
$$

\subsubsection{Pumps}

Pumps are used to pressurize fuel flow. Two types of pumps, i.e. centrifugal pumps as low pressure pumps and gear pumps as high pressure pumps are normally used.

In this study, empirical pump characteristic maps are used to describe the performance behavior of the pumps. Four characteristic parameters including shaft relative rotational speed $P C N$, volumetric flow rate $Q$, efficiency $\eta$, and pressure increase $\Delta P$ are used to describe the pump characteristics. When any two of the parameters are given, the other two parameters can be obtained through the interpolation of the maps.

As pumps are directly connected to engine shaft, pump shaft rotational speed is assumed to be equal to the engine shaft speed and there is no time delay.

The energy transformed to the fuel flow can be divided into two parts, one is used to pressurize the fuel flow and the other is to increase fuel temperature. In other words, pump shaft power (PSP) can be obtained by Eq. (13) [25-26]

$$
P S P=\frac{\Delta P \times Q}{\eta}
$$

The temperature rise $\Delta T$ of the fuel flow can be calculated by Eq. (14).

$$
\Delta T=\frac{\phi}{W \times C p}
$$

Where

$$
\phi=P S P \times(1-\eta)
$$




\subsubsection{Valves}

Valves are the devices to regulate and control fuel flow rate. A constant pressure differential valve (CPDV) is a device to maintain a constant pressure drop across a fuel metering unit (MU). A metering unit is the device to meter the engine required fuel flow rate based on the controller order. A throttle is the device to constrict or obstruct the fuel flowing through it. An injector is used to deliver the metered fuel flow into an engine combustor.

The MU and the CPDV are able to change orifice area depending on fuel flow demand. For these components, the orifice area is determined by the pressure drop across the orifice and the required volume fuel flow rate so it can be estimated by Eq. (16).

$$
A=\frac{Q}{C_{d}} \times \sqrt{\frac{\rho}{2 \Delta P}}
$$

The required orifice area can be obtained by moving the accessary mechanism with the moving distance $\Delta X d$ estimated by Eq. (17).

$$
\Delta X d=\Delta A_{c} / k
$$

A first order lag represented by a Laplace transfer function $\frac{1}{T_{m} s+1}$ is added to represent the delay time $\left(4 T_{m}\right)$ of the mechanical movement corresponding to the moving distance variation $\Delta X d$. The moving distance of the valves $X d_{i+1}$ in one time step can be calculated by Eq. (18).

$$
X d_{i+1}=X d_{i}+\Delta X d \times \frac{1-e^{-\frac{\Delta t}{T_{m}}}}{z-e^{-\frac{\Delta t}{T_{m}}}}
$$

For the throttle and the injector whose orifice areas are fixed, the fuel volumetric flow rate can be calculated by Eq. (19) [25].

$$
Q_{f f}=C d \times A \times \sqrt{\frac{2 \Delta P}{\rho}}
$$

The fuel spray delay effect in the injector is also considered as a first order lag and is calculated by Eq. (20). 


$$
W_{f f}=Q_{f f} \times \frac{1-e^{-\frac{\Delta t}{T_{f}}}}{z-e^{-\frac{\Delta t}{T_{f}}}} \times \rho
$$

\subsection{Integrated Engine, Controller and Fuel System}

Fig. 6 shows the calculation flow chart for the integrated fuel system represented by Fig. 4. The fuel system performance calculation process follows the fuel flow path in the system. For each calculation time step, if a required parameter of a component is from its down-stream component, the value of this parameter will take the value of the same parameter at the previous time step.

The integrated engine, fuel and control system calculation flow chart has been established and shown in Fig. 7. In this integrated system model, the gas turbine drives the fuel system via a shaft connection. Therefore, the shaft power surplus $S P$ in Eq. (1) can be obtained by Eq. (21).

$$
S P=W_{t}-W_{c}-\sum P S P
$$

It is assumed that only the pump power consumption PSP represents the total power consumption of the whole fuel system.

It is assumed that the measured engine shaft speed is transmitted to the engine fuel controller with a first order

$\operatorname{lag} \frac{1}{T_{s} s+1}$. The controller receives the measured speed signal and calculates the required fuel flow rate $Q_{f f}$ using the PI control schedule. The demand of $Q_{f f}$ is then turned into the fuel flow $W_{f f}$ injected into the engine combustor to maintain the engine operation.

\section{Application and Analysis}

\subsection{Model Engine}

The developed integrated engine, control and fuel system transient performance simulation method has been applied to a model aircraft engine shown in Fig. 1 where the shaft relative rotational speed PCN is chosen as the 
engine handle and controlled by the controller to determine the operating condition of the engine. Table 1 lists the engine performance specification and the key performance parameters.

\subsection{Model Fuel System}

The model fuel system used in this study is shown in Fig. 2 and its key parameters and their design point values are shown in Table 2.

The characteristic map shown in Fig. 8 is for the centrifugal pump and the gear pump has a similar map. The efficiency of each pump is assumed to be constant for simplicity although efficiency maps may describe more accurate pump behavior [27]. The developed ICV method for fuel systems was applied to the fuel system of the model engine. The control gains of the PI controller are given in Table 3 where the values of the gains were obtained via trials and errors to ensure that the acceleration and deceleration processes are quick and safe without big oscillations.

\subsection{Engine Model Validation}

Two performance models have been set up, one with the developed software and the other using GasTurb [9], well developed commercial software. To ensure the accuracy of the developed engine performance model, the model has been validated against GasTurb [9] at both steady state and transient operation conditions. An example of the comparison between the developed model and GasTurb is shown in Fig. 9 where the relative shaft rotational speed and fuel flow rates from both models are shown. It can be seen that although there are some errors at certain points due to the fuel schedules and component maps used in the two models are slightly different, the results from the developed model show the same trends as that of GasTurb. This demonstrates that the developed engine model is reasonably good for current study.

\subsection{Transient Performance Simulation}

The transient performance of the model engine has been simulated using the system shown in Fig. 7. It is assumed that the model engine is running at an altitude of $1000 \mathrm{~m}$ and at Mach number 0.5. It is also assumed that the engine starts acceleration from its steady state condition at PCN of $70 \%$, accelerates to its maximum power at PCN of $100 \%$, stays for about 20 seconds and then decelerates back to the PCN of $70 \%$. 
Fig. 10 shows the PCN command signal against the actual PCN variation during the whole transient process of 30 seconds. Fig. 11 shows a comparison of the trajectories among the actual fuel flow variation, the fuel schedule and the fuel flow rate at steady state.

To demonstrate the impact of the inclusion of the fuel system model, a comparison of the simulated transient process with and without the fuel system model is made as shown in Fig. 12 where the delayed transient response by about 0.5 second due to the inclusion of the fuel system model is obvious. The most significant delays happen at the points where the fuel flow control is switched between the fuel schedule and the PI fuel controller. This is due to the delay caused by the action of the fuel system components and the effect of the inter-component volumes. Other engine parameters, such as $P C N$ and turbine entry temperature, also show similar variations and are not shown here due to limited space available.

It can be seen from the results that the time delay due to the inclusion of the fuel system model is noticeable but relatively small. However, the introduction of the physics-based fuel system model allows the simulation of detailed behavior of fuel systems and to understand the mechanism of variations. It can be applied to more complicated fuel systems and engines where the time delay may become more significant. Therefore it could be very useful to simulate and analyze the root cause of time delay and to assist design engineers to improve the fuel system and engine designs whenever is necessary.

\section{Conclusions}

A novel transient performance simulation method for engine hydraulic fuel system based on an inter-component volume (ICV) method has been introduced. It allows physics-based simulation models to be built up for gas turbine engines with the inclusion of control and fuel systems, which is potentially more accurate than using transfer functions. The application of the developed fuel system simulation method to the transient performance simulation of a model aero engine shows that the maximum time delay of engine performance during the transient process due to the inclusion of the fuel system model and the inter-component volumes is around 0.5 second at the time when the fuel control is switched between the fuel schedule and the fuel controller. Such delay is noticeable but relatively

small. The new physics-based simulation method offers more detailed simulation of fuel systems, assists better understanding of their working mechanism, be able to investigate the root cause of variations and supports engine 
and fuel system designs. It is a better alternative to the modelling approaches for hydraulic fuel systems based on transfer functions.

\section{References}

[1] Lytle J. K., "The Numerical Propulsion System Simulation: A Multidisciplinary Design System for Aerospace Vehicles", NASA TM-209194, 1999.

[2] Lytle J. K., "The Numerical Propulsion System Simulation: An Overview", NASA TM-209915, 2000.

[3] Naiman C. G., and Follen G. J., "Numerical Propulsion System Simulation - A Common Tool for Aerospace Propulsion Being Developed", NASA TM-210605, 2001.

[4] May R. D., Csank J., Lavelle T. M., Litt J. S. and Guo T. H., “A High-Fidelity Simulation of a Generic Commercial Aircraft Engine and Controller", $46^{\text {th }}$ AIAA/ASME/SAE/ASEE Joint Propulsion Conference \& Exhibit, Nashville, TN, 2010.

[5] Frederick D. K., DeCastro J. A., and Litt J. S., "User's Guide for the Commercial Modular Aero-Propulsion System Simulation (C-MAPSS)", NASA TM-215026, 2007.

[6] Palmer J. R., “Turbocode Scheme for the Programming of the Thermodynamic Cycle Calculations on an Electronic Digital Computer", College of Aeronautics, Cranfield, Rept. COA/AERO-198, 1967.

[7] Macmillan W. L., "Development of a Modular Type Computer Program for the Calculation of Gas Turbine Off Design Performance", Ph.D. Thesis, Cranfield University, 1974.

[8] Kurzke J., "Advanced User-Friendly Gas Turbine Performance Calculations on a Personal Computer", 95-GT-147, ASME International Gas Turbine and Aeroengine Congress and Exposition, Houston, Texas, USA, 1995.

[9] GasTurb web site URL: “http: //www.gasturb.de”, Jun. 2013.

[10] Visser W. P. J. and Broomhead M. J., “GSP, a generic object-oriented gas turbine simulation environment”, 2000-GT-0002, ASME Turbo Expo 2000, Munich, Germany, 2000.

[11] Visser W. P. J., Broomhead M. J. and van der Vorst J., "TERTS, a generic real-time gas turbine simulation environment”, 2001-GT-0446, ASME Turbo Expo 2001, New Orleans, Louisiana, USA, 2001.

[12] Chapman J.W., Lavelle T.M., May R.D., Litt J.S. and Guo T.H., "Toolbox for the Modeling and Analysis of Thermodynamic Systems (T-MATS) User's Guide”, NASA/TM-2014-216638, 2014.

[13] Somehsaraei H.N., Majoumerd M.M., Breuhaus P. and Assadi M., "Performance analysis of a biogas-fueled micro gas turbine using a validated thermodynamic model", Applied Thermal Engineering, Vol. 66, pp. 181-190, 2014.

[14] Jaw L. C. and Mattingly J. D., “Aircraft Engine Controls: Design, System Analysis, and Health Monitoring”, AIAA Education Series, AIAA, Reston, 2009, pp. 51-57. 
[15] US Department of Transportation, “Airframe \& Powerplant Mechanics: Powerplant Handbook”, Federal Aviation Administration, 1976, pp. 315-330.

[16] Fawke A. J. and Saravanamuttoo H. I. H., "Digital Computer Methods for Prediction of Gas Turbine Dynamic Response", SAE Technical Paper 710550, 1971.

[17] Sellers J. F. and Daniele C. J., "DYNGEM. A Program for Calculating Steady State and Transient Performance of Turbojet and Turbofan Engines", NASA TN D-7901, 1975.

[18] Szuch J. R., "HYDES, A Generalized Hybrid Computer Program for Studying Turbojet or Turbofan Engine Dynamics", NASA TM X-3014, 1974.

[19] Koening R. W. and Fishbach L. H., “GENENG, A Program for Calculating Design and Off-Design Performance for Turbojet and Turbofan Engines", NASA TN D-6552, 1972.

[20] Larrowe V. L., Spencer M. M. and Tribus M., “A Dynamic Performance Computer for Gas Turbine Engines”, Industry Program of the College of Engineering, Michigan Univ., 1957.

[21] Rahman N. U. and Whidborne J. F., "A Numerical Investigation into the Effect of Engine Bleed on Performance of a Single-Spool Turbojet Engine”, Journal of Aerospace Engineering, Vol. 222, No. 7, 2008, pp. 939-949.

[22] Benner S., “A History of Control Engineering 1930-1955”, IEE, London, UK, 1993, Chap. 2.

[23] Wikipedia URL: http://en.wikipedia.org/wiki/PID controller, accessed in Jan. 2015.

[24] Astrom K. and Hagglund T., “Controllers: Theory, Design and Tuning”, $2^{\text {nd }}$ edition, Chapter 2, 1995.

[25] Fan S. Q., Li D. and Fan D., “Aero Engine Control (Part One)” (in Chinese), Northwestern Polytechnical University, China, 2009.

[26] Pu Z. L., “Aviation Pump Design” (in Chinese), National Defense Industry Press, China, 1983.

[27] Menon E.S. and Menon P.S., "Working Guide to Pumps and Pumping Stations", Gulf Publishing Company, 2009. 


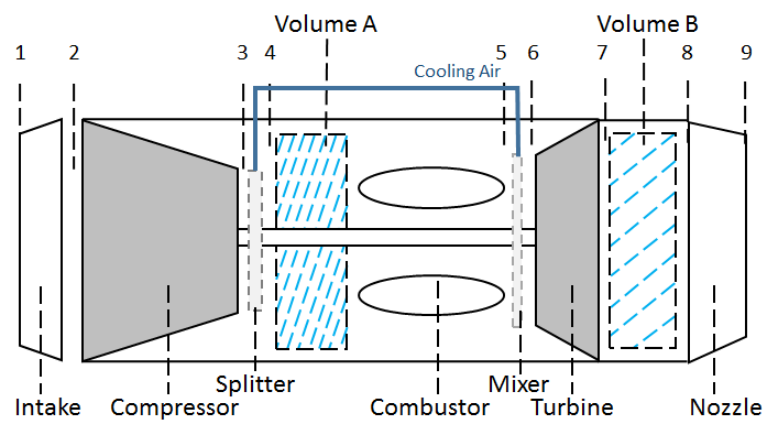

Fig. 1 Schematic of Single-Spool Turbojet Model Engine Configuration

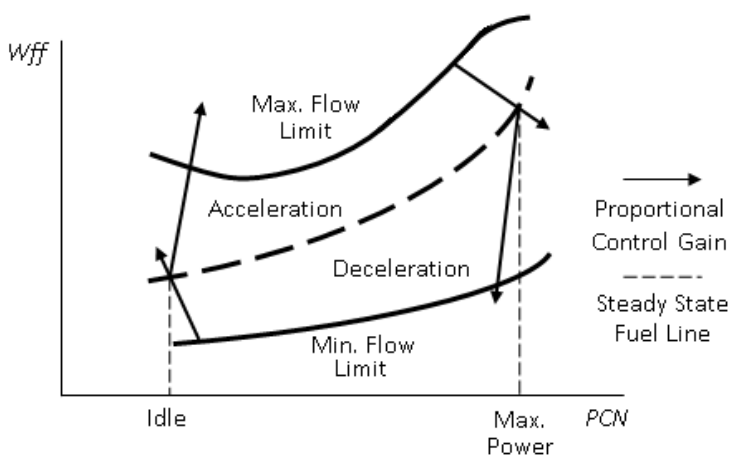

Fig. 2 Fuel Schedule of Model Engine 


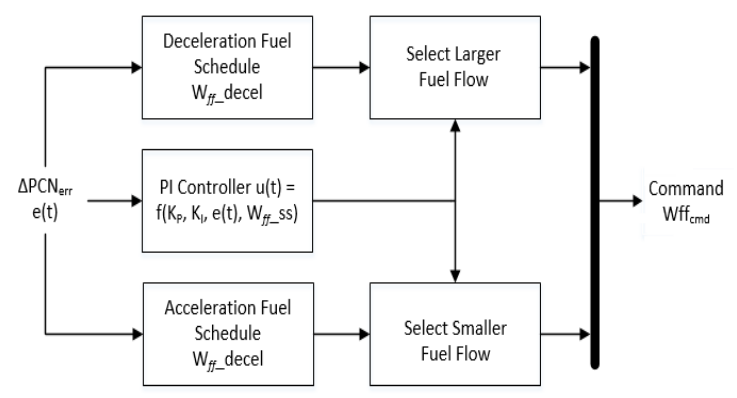

Fig. 3 Diagram of Coupled Engine Controller and Fuel Selection Logic

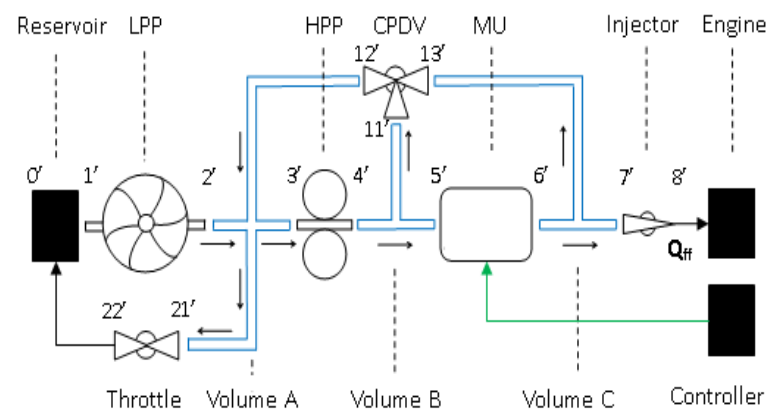

Fig. 4 Schematic of Engine Fuel System 


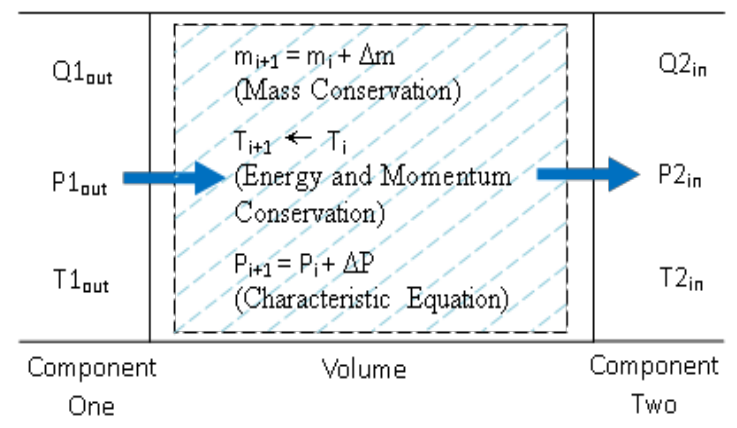

Fig. 5 Inter-Component Volume

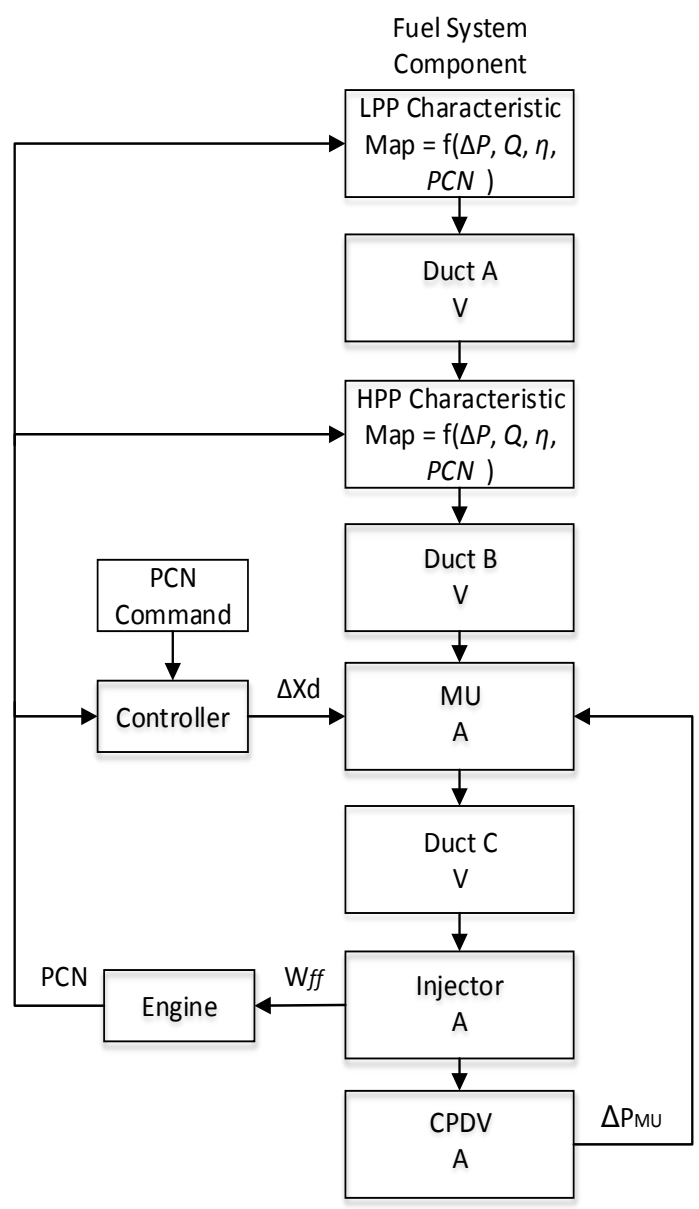

Fig. 6 Flow Chart of Fuel System Model 


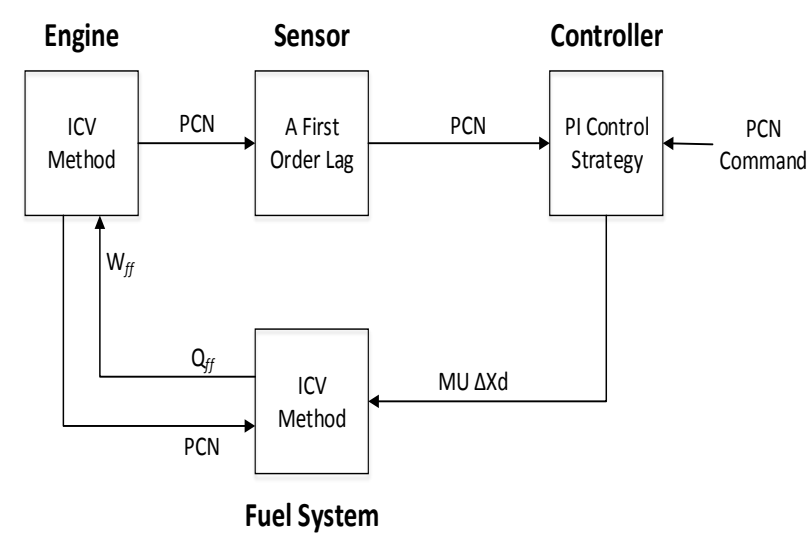

Fig. 7 Schematic of Integrated Engine, Controller and Fuel System

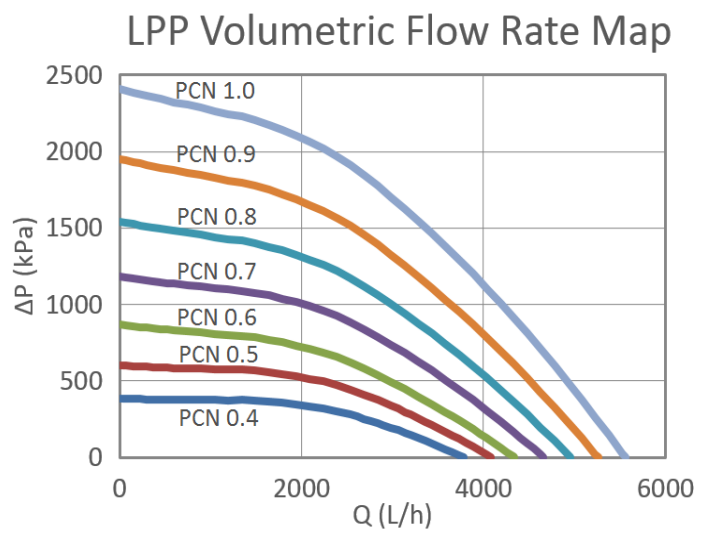

Fig. 8 Characteristic Map of Centrifugal Pump 


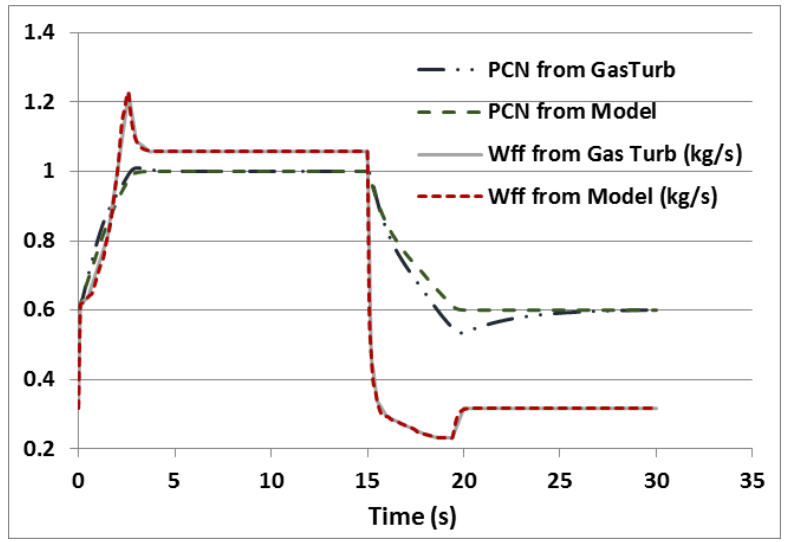

Fig. 9 Comparison between Developed Model and GasTurb [9] at Transient Process (Altitude $=1000 \mathrm{~m}$, Mach number $=0.5$ )

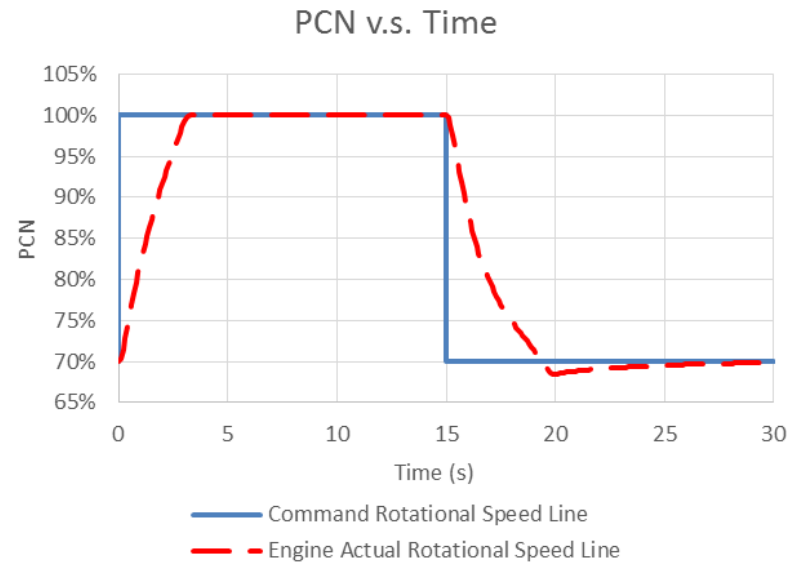

Fig. 10 PCN v.s. Time at Altitude $=1000 \mathrm{~m}$, Mach number $=0.5$ 


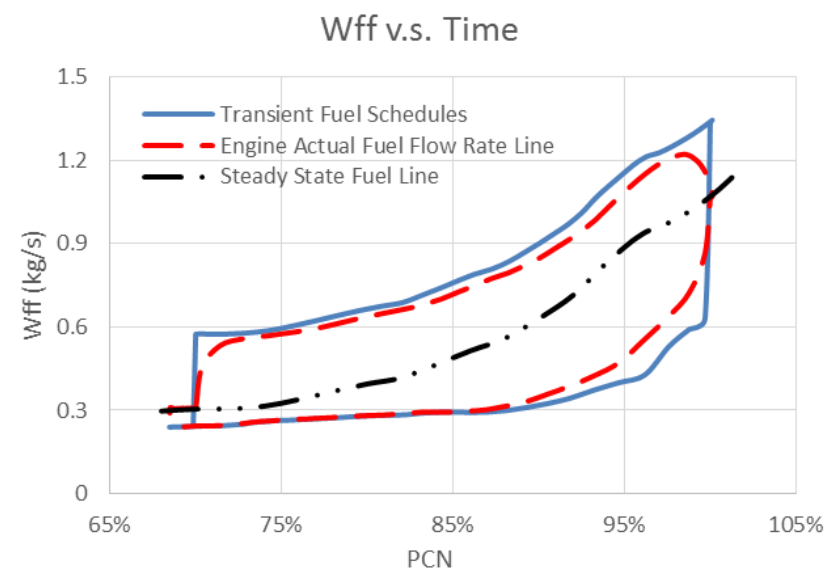

Fig. $11 W_{\text {ff }}$ v.s. PCN at Altitude $=1000 \mathrm{~m}$, Mach number $=0.5$

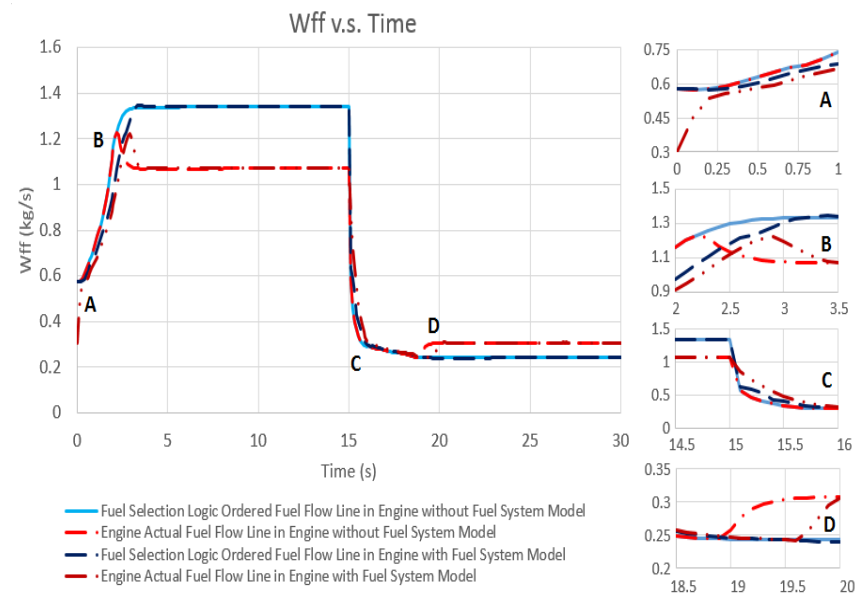

Fig. 12 Transient Fuel Schedule Comparison between Engine with and without Fuel System Model 
Table 1 Engine Performance Specification at Sea level static ISA condition

\begin{tabular}{|l|c|}
\hline \multicolumn{1}{|c|}{ Parameters } & Value \\
\hline Air Flow Rate $(\mathrm{kg} / \mathrm{s})$ & 77.2 \\
\hline Compressor Pressure Ratio & 8.8 \\
\hline Compressor Isentropic Efficiency & 0.84 \\
\hline Combustion Efficiency & 0.99 \\
\hline Volume A $\left(\mathrm{m}^{3}\right)$ & 0.4 \\
\hline Turbine Entry Temperature (TET) (K) & 1089 \\
\hline Turbine Isentropic Efficiency & 0.87 \\
\hline Volume B $\left(\mathrm{m}^{3}\right)$ & 0.2 \\
\hline Thrust $(\mathrm{kN})$ & 47.28 \\
\hline SFC $(\mathrm{g} / \mathrm{kN} \cdot \mathrm{s})$ & 22.36 \\
\hline
\end{tabular}

Table 2 Fuel System Parameters at Design Point

\begin{tabular}{|c|c|c|}
\hline \multicolumn{2}{|c|}{ Component } & Value \\
\hline \multirow{3}{*}{$\begin{array}{l}\text { Low } \\
\text { Pressure } \\
\text { Pump }\end{array}$} & Fuel Flow Rate (L/h) & 7139.6 \\
\hline & Pressure Rise $(\mathrm{kPa})$ & 600 \\
\hline & Efficiency & 0.6 \\
\hline Volume A & Volume $\left(\mathrm{m}^{3}\right)$ & 0.0001 \\
\hline Throttle & Fuel Flow Rate (L/h) & 4000 \\
\hline \multirow{3}{*}{$\begin{array}{l}\text { High } \\
\text { Pressure } \\
\text { Pump }\end{array}$} & Fuel Flow Rate (L/h) & 7615.4 \\
\hline & Pressure Rise $(\mathrm{kPa})$ & 3500 \\
\hline & Efficiency & 0.8 \\
\hline Volume B & Volume $\left(\mathrm{m}^{3}\right)$ & 0.00003 \\
\hline \multirow{3}{*}{$\begin{array}{l}\text { Metering } \\
\text { Unit }\end{array}$} & Fuel Flow Rate $(\mathrm{L} / \mathrm{h})$ & 4759.7 \\
\hline & Pressure Drop $(\mathrm{kPa})$ & 400 \\
\hline & Opening Coefficient & 0.009 \\
\hline Volume C & Volume $\left(\mathrm{m}^{3}\right)$ & 0.00003 \\
\hline \multirow[t]{2}{*}{ Injector } & Fuel Flow Rate (L/h) & 4759.7 \\
\hline & Area $\left(\mathrm{mm}^{2}\right)$ & 28.5 \\
\hline
\end{tabular}

Table 3 PI Controller Gains

\begin{tabular}{|l|c|}
\hline Proportional Gain $K_{\mathrm{P}}$ & 8 \\
\hline Integral Gain $K_{\mathrm{I}}$ & 1.8 \\
\hline
\end{tabular}


Transient Performance Simulation of

\section{Aircraft Engine Integrated with Fuel and Control Systems}

\section{Wang, Chen}

\section{Elsevier}

Wang C, Li YG, Yang BY. Transient Performance Simulation of Aircraft Engine Integrated with pÿFuel and Control Systems. Applied Thermal Engineering, Volume 114, 5 March 2017, Pages 10291037 http://dx.doi.org/10.1016/j.applthermaleng.2016.12.036

Downloaded from Cranfield Library Services E-Repository 